\title{
Long-Term Neural Correlates of Reversible Fear Learning in the Lateral Amygdala
}

\author{
Bobae An, ${ }^{*}$ Ingie Hong, ${ }^{\star}$ and Sukwoo Choi \\ School of Biological Sciences, College of Natural Sciences, Seoul National University, Seoul 151-742, Republic of Korea
}

Fear conditioning and extinction are behavioral models that reflect the association and dissociation of environmental cues to aversive outcomes, both known to involve the lateral amygdala (LA). Accordingly, responses of LA neurons to conditioned stimuli (CS) increase after fear conditioning and decrease partially during extinction. However, the long-term effects of repeated fear conditioning and extinction on LA neuronal firing have not been explored. Here we show, using stable, high signal-to-noise ratio single-unit recordings, that the ensemble activity of all recorded LA neurons correlates tightly with conditioned fear responses of rats in a conditioning/ extinction/reconditioning paradigm spanning $3 \mathrm{~d}$. This CS-evoked ensemble activity increased after conditioning, decreased after extinction, and was repotentiated after reconditioning. Cell-by-cell analysis revealed that among the LA neurons that displayed potentiated responses after initial fear conditioning, some exhibited weakened CS responses after extinction (extinction-susceptible), whereas others remained potentiated (extinction-resistant). The majority of extinction-susceptible neurons exhibited strong potentiation after reconditioning, suggesting that this distinct subpopulation (reversible fear neurons) encodes updated CS- unconditioned stimulus (US) association strength. Interestingly, these reversible fear neurons displayed larger, more rapid potentiation during reconditioning compared with the initial conditioning, providing a neural correlate of savings after extinction. In contrast, the extinction-resistant fear neurons did not show further increases after reconditioning, suggesting that this subpopulation encodes persistent fear memory representing the original CS-US association. This longitudinal report on LA neuronal activity during reversible fear learning suggests the existence of distinct populations encoding various facets of fear memory and provides insight into the neuronal mechanisms of fear memory modulation.

\section{Introduction}

Fear conditioning is the association of a neutral conditioned stimuli (CS) to an aversive unconditioned stimulus (US), leading to fearful responses to CS-alone presentations (LeDoux, 2000). After fear memory consolidation, which requires $>4-6$ h (McGaugh, 2000; Schafe et al., 2000), fear memory becomes remarkably resistant to perturbation, giving way only to numerous unreinforced CS presentations, which leads to the extinction of learned fear responses. However, substantial remnants of the originally learned fear survive even after extensive extinction and causes the reappearance of fear-related behavior in a variety of circumstances, such as fear renewal and facilitated reacquisition (Bouton, 2002). These observations suggest that extinction does not lead to complete reversal of learning, but

Received June 26, 2012; revised Aug. 31, 2012; accepted Sept. 24, 2012.

Author contributions: B.A., I.H., and S.C. designed research; B.A. and I.H. performed research; B.A., I.H., and S.C. analyzed data; B.A., I.H., and S.C. wrote the paper.

This work was supported by the Original Technology Research Program for Brain Science through the National Research Foundation (NRF) of Korea funded by the Ministry of Education, Science and Technology (2011-0019226), and also supported by the NRF of Korea grant funded by the Korea government (MEST) (No. 2011-0018209, 20090081349). B.A. was supported by Brain Korea 21 Research Fellowships from the Korean Ministry of Education and I.H. was supported by the NRF of Korea (2012R1A6A3A01019438). Pacific Edit reviewed this manuscript prior to submission. We thank Min Whan Jung, Denis Paré, and Inah Lee for valuable comments on this manuscript and Kay M. Tye, Cyril Herry, and Jung Hoon Sul for kind advice on in vivo unit recording techniques.

*B.A. and I.H contributed equally to this work.

Correspondence should be addressed to Dr. Sukwoo Choi, School of Biological Sciences, Seoul National University, Seoul, 151-742, Republic of Korea. E-mail: sukw0012@snu.ac.kr.

DOI:10.1523/JNEUROSCI.3017-12.2012

Copyright $\odot 2012$ the authors $\quad 0270-6474 / 12 / 3216845-12 \$ 15.00 / 0$ rather a unique state in which original fear traces are inhibited temporarily. The mechanisms of subsequent relearning are largely unknown, although it is well known that such relearning occurs both more rapidly and with a lower threshold (i.e., savings; Napier et al., 1992; Macrae and Kehoe, 1999).

The lateral amygdala (LA) is essential in the acquisition and consolidation of auditory cued-fear conditioning (Davis, 1992; Blair et al., 2001). Thalamic and cortical auditory inputs to the LA are potentiated after fear conditioning (McKernan and ShinnickGallagher, 1997; Quirk et al., 1997; Tsvetkov et al., 2002), which are relayed to the basal and central amygdala so as to evoke aversive behavior (LeDoux, 2000; Davis and Whalen, 2001). Fear extinction recruits the infralimbic cortex to exert inhibitory influence on the medial subnuclei of the central amygdala (CeM) via the basal amygdala (BA) and amygdala-intercalated neurons (Maren and Quirk, 2004; Haubensak et al., 2010; Pape and Pare, 2010; Amir et al., 2011). Extinction also induces depotentiation at LA input synapses (Kim et al., 2007; Dalton et al., 2008; Hong et al., 2009) and enhances local inhibition (Chhatwal et al., 2005; Lin et al., 2009), all leading to decreased fear expression. Interestingly, NMDA receptor blockers infused into the LA impair both fear conditioning and extinction, suggesting that neuronal plasticity in the LA is crucial for both events (Miserendino et al., 1990; Falls et al., 1992; Sotres-Bayon et al., 2007). Reconditioning has been less well explored, and although savings has been regarded as proof of the persistence of memory after extinction, the neural substrates that support this rapid relearning are largely unknown. 
Previous LA unit recording studies have demonstrated that amygdala neurons increase their response to conditioned stimuli and decrease partially when the stimuli become less fearful (Quirk et al., 1995; Collins and Paré, 2000; Repa et al., 2001; Goosens et al., 2003). Most of these reports used relatively short behavioral procedures over a day or two, thus falling short of demonstrating the longterm modulation of fear memory involving extensive extinction and subsequent relearning. We thereby used high signalto-noise ratio (SNR) fixed-microwire recordings to track longitudinal changes in neuronal firing during a $3 \mathrm{~d}$ procedure encompassing fear conditioning, extinction, and reconditioning. Our results reveal distinct subpopulations in the LA that persistently represent the original CS-US association or dynamically encode updated CS-US association throughout the course of reversible fear learning.

\section{Materials and Methods}

Animals. Male Sprague Dawley rats $(n=45,8$ weeks old) were individually housed for $4-5 \mathrm{~d}$ before all experiments under an inverted $12 \mathrm{~h}$ light/dark cycle (lights off at 9:00 A.M.) and provided with food and water ad libitum. Behavioral training was done in the dark portion of the cycle. All procedures were approved by the Institute of Laboratory Animal Resources of Seoul National University.

Surgery and recording. Rats were anesthetized with sodium pentobarbital $\left(50 \mathrm{mg} / \mathrm{kg}\right.$, i.p.) and maintained with isoflurane (1-1.5\%) in $\mathrm{O}_{2}$. Rats were secured in a stereotaxic frame and bilaterally implanted with fixed-wire electrodes targeted to the LA: $2.8 \mathrm{~mm}$ posterior to bregma, 5.2 $\mathrm{mm}$ lateral to midline, and 6.3-6.9 $\mathrm{mm}$ deep from the cortical surface. The electrodes consisted of eight individually insulated nichrome microwires (50 $\mu \mathrm{m}$ outer diameter, impedance $0.5-1 \mathrm{M} \Omega$ at $1 \mathrm{kHz}$; California Fine Wire) contained in a 21 gauge stainless steel guide cannula. The implant was secured using dental cement (Vertex). After surgery, analgesia (Metacam; Boehringer) and antibiotics were applied and rats were allowed to recover for 6-7 d. Neural activity was acquired and analyzed using a Plexon MAP system, as previously described (Herry et al., 2008).

Behavioral procedures. Fear conditioning and extinction took place in two different contexts (context A and B) (Fig. 1A) to minimize the influence of contextual associations. Reconditioning was conducted in the same context as extinction to avoid renewal and to observe savings. Context A was a rectangular Plexiglas box with a metal grid floor connected to an electrical current source (Coulbourn Instruments), which was set in a sound-attenuating chamber. The chamber was illuminated with white light and was cleaned with a 70\% ethanol solution. Context B was a cylindrical Plexiglas chamber with a metal grid floor, which was illuminated with a red light and was cleaned with $1 \%$ acetic acid. In the retention test for the second unpairing (Post-UP2), a different context (context C) was used to avoid contextual fear. Context $\mathrm{C}$ was a trapezoid black opaque box with a flat black Formica floor illuminated with a red light that was cleaned with scented soap. All of the training sessions were videotaped and conditioned freezing was quantified by trained observers. The animals were considered to be freezing when there was no movement except for respiratory activity for $2 \mathrm{~s}$ during the $30 \mathrm{~s}$ CS presentation. The total freezing time was normalized to the duration of the CS presentation (Kim et al., 2010). On day 1, rats were habituated to the context and the CS in context $\mathrm{A}$, in which they were placed in the
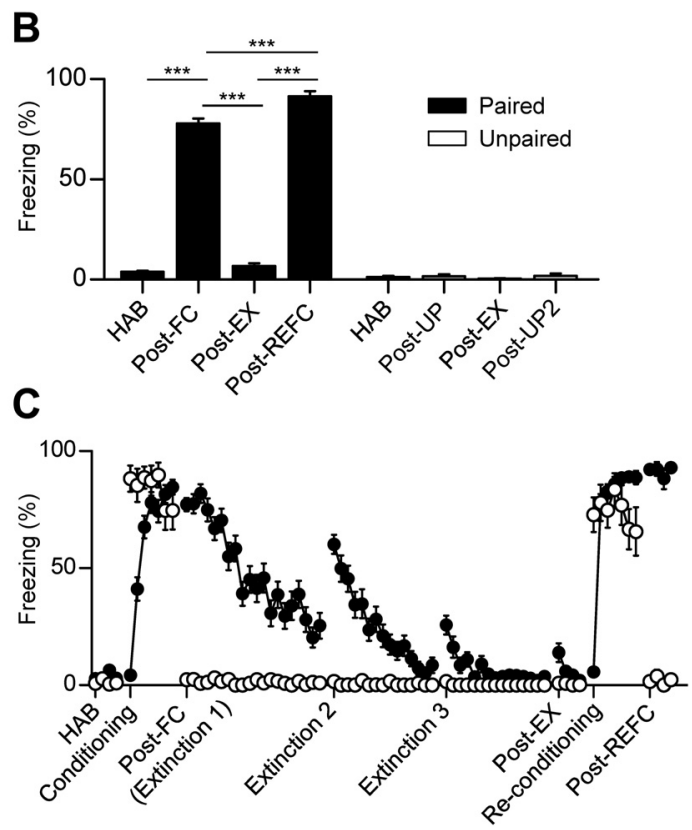

Figure 1. Reversible fear learning dynamically regulates defensive behavior. $\boldsymbol{A}$, The behavioral procedure used in the experi-

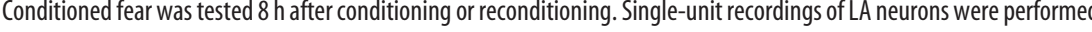
during the first four CS presentations of the retention test sessions (bold characters in $\boldsymbol{A}$ ) in each group (paired group, $n=32$ rats; unpaired controls, $n=13$ rats). $C$, The learning curves of the entire behavioral session (paired group, filled circle; unpaired controls, EM. ${ }^{* * *} p<0.0001$.

recording chamber twice for $10 \mathrm{~min}$, first without any cue and later with four presentations of the CS. The CS was a 29.089 s series of $272.8 \mathrm{kHz}$ pure tone pips ( $200 \mathrm{~ms}$ duration repeated at $0.9 \mathrm{~Hz}, 85 \mathrm{~dB}$ sound pressure level), which has been used previously to enhance the SNR for neural recordings (Rogan et al., 1997; Repa et al., 2001; Herry et al., 2008). On day 2, rats were given four presentations of the CS to determine basal LA neural responses to the CS (HAB). An hour later, fear conditioning was conducted by pairing the CS with a mild electric foot shock $(0.5 \mathrm{~mA}, 1 \mathrm{~s}$, 7 CS/US pairings; intertrial interval: $80-120 \mathrm{~s}$ ) coinitiating with the onset of the last tone pip. Extinction training took place $8 \mathrm{~h}$ after fear conditioning in context $\mathrm{B}$, in which rats were presented with 20 nonreinforced CS presentations (Post-FC). Two additional extinction sessions were conducted on the next day. On day 4, the behavioral and neuronal outcome of three extinction sessions was observed in a short four CS test session (Post-EX), followed $1 \mathrm{~h}$ later by the reconditioning session in a manner similar to the initial fear learning. Eight hours after reconditioning, a retention test session was conducted (Post-REFC). To control for nonassociative effects of conditioning, a separate group of rats (unpaired group, $n=13$ ) was exposed to explicitly unpaired CS and US presentations during the conditioning and reconditioning sessions, with all the other procedures applied identically.

Single-unit spike sorting and analysis. Unit discrimination was performed using Offline Sorter (Plexon). All waveforms were plotted in a principal component space and clusters consisting of similar waveforms were first defined automatically and then verified manually. A cluster of waveforms distinct from other clusters in principal component space and showing a clear refractory period ( $>1 \mathrm{~ms}$ ) was considered to be generated from a single neuron. At most, two distinct units were identified per channel, and single-channel recordings proved sufficient to discern single-unit responses, due to the low neuronal density of the LA (Quirk et al., 1997; Paré et al., 2004). Single-unit isolation was graded using two statistic parameters, $\mathrm{J} 3$ and the Davies-Bouldin validity metric (DB), and neurons with a low grade were discarded. J3 reflects the ratio of betweencluster separation to within-cluster density calculated in a principal component space, and the DB is the ratio between the sum of within-cluster density to the degree of separation between clusters, and thus a high J3 and low DB value indicates a compact, well separated unit cluster 
(Nicolelis et al., 2003). The long-term stability of a single-unit isolation was first determined using Wavetracker (Plexon), in which the principal component space cylinders of a unit recorded from different sessions were plotted (Herry et al., 2008; Tseng et al., 2011). A straight cylinder suggests that the clusters of a unit have a similar principal component composition, and that the same set of single units was recorded during the entire training session. Next we calculated the linear correlation values $(r)$ between the template waveforms obtained over the entire set of behavioral sessions (Jackson and Fetz, 2007) to evaluate the similarity of waveform shape. Only stable units $(r>0.93)$ were considered for further analysis.

To investigate the effects of training on the LA cells, CS-evoked neural activities were normalized using a standard $z$-score transformation (bin size, $10 \mathrm{~ms}$ ). We adopted a moving average baseline (Paré and Gaudreau, 1996; Oyama et al., 2010) to exclude possible errors arising from extremely low spontaneous firing rates of the LA, and to reflect the insession changes of basal firing rate. Unit responses were normalized to the firing rates of $500 \mathrm{~ms}$ preceding tone pip onset for three consecutive CS (81 individual tone pips in total), except for units that did not exhibit any firing within this interval, which were normalized to the basal firing rates calculated from all pre-pip intervals of the session. $Z$-score perievent time histograms (PETHs) of averaged CS responses were constructed for each neuron and each pip and then averaged for every CS (27 tone pips). A unit was regarded as being CS-onset or CS-offset responsive if the firing in two consecutive bins within $100 \mathrm{~ms}$ following CS-onset or CS-offset was significantly different from the baseline $(500 \mathrm{~ms}$ preceding the CS) in an averaged PETH of all training sessions $(p<0.05$, one-tailed $t$ test) (Quirk et al., 1995). The onset latency of the CS-evoked responses was defined as the first bin to become significantly different from the baseline, and the bin that displayed the greatest firing within the $100 \mathrm{~ms}$ interval provided the peak response latency. To investigate the effects of behavioral training on the entire LA neuronal population, the population $z$-score PETH of all recorded neurons was calculated for each CS consisting of 27 tone pips and the mean $z$-values of $0-100 \mathrm{~ms}$ following CSonset and CS-offset from the first four CSs of each session were compared throughout the course of behavioral training. The mean $z$-values in the two conditioning sessions were calculated using the first 25 tone pips of the CS to avoid foot shock-induced artifacts in the last pips.

Cell-by-cell analysis was further conducted to explore the effects of reversible fear learning on individual LA neurons. Analysis was restricted to neurons that were responsive to CS onset. To determine responsiveness in each session, the CS-response PETHs of four CS (108 individual tone pips in total) were averaged and the maximum $z$-score of the $0-100$ ms interval after CS onset was calculated for each neuron and compared with the significant $z$-score, 1.65 ( $p<0.05$, one-tailed $t$ test) (Herry et al., 2008). A neuron was determined to be a fear neuron if it exhibited significant CS-evoked responses in fear memory recall sessions (Post-FC or Post-REFC) and increased responses relative to the preceding sessions (HAB or Post-EX). We also sought extinction neurons, defined as neurons displaying strong CS responses only after the extinction session (Post-EX), but found only one, and thus the characteristics of the fear neurons were compared with all of the other CS-responsive neurons.

Histology. At the end of each experiment, rats were anesthetized with urethane $(1 \mathrm{~g} / \mathrm{kg}$, i.p. $)$ and electrolytic lesions were made by passing a current (10 $\mu \mathrm{A}, 5-20 \mathrm{~s})$ through recording microwires from which discrete units were identified. The duration of current injection was varied among recording microwires to identify the exact region where each unit was located. Longer current injections produced larger and more visible lesions. Animals were then transcardially perfused with $0.9 \%$ saline solution and $10 \%$ buffered formalin. Brains were removed and postfixated overnight. Coronal sections (90 $\mu \mathrm{m}$ thick) were obtained using a vibroslicer (NVSL; World Precision Instruments) and stained with cresyl violet. The placement of the recording microwires was examined under a light microscope.

Statistical analysis. To compare the behavioral results among training sessions, averaged data points were analyzed using repeated-measures ANOVA with subsequent Newman-Keuls post hoc comparison. The CS responsiveness of LA units was determined using unpaired $t$ tests. For the analysis of CS responses of LA subpopulations, the Friedman test (nonparametric one-way ANOVA for repeated measurements) and subsequent Dunn's post hoc tests were used (Duclos et al., 2008). To detect changes in the CS responses of the entire LA ensemble average activity (including both CS-responsive and nonresponsive units), the linear sum of all CS-evoked activity was computed and the tone-to-tone variation was used for statistical deduction with parametric one-way ANOVA and NewmanKeuls post hoc tests. Correlation between neuronal firings and behavioral responses were calculated using Pearson's correlation test. A probability value of $p<0.05$ was considered indicative of statistical significance.

\section{Results}

\section{Reversible fear learning dynamically regulates defensive behavior}

A total of 32 rats underwent a reconditioning paradigm as described previously (see Materials and Methods) (Fig. 1A) and their fear levels to the CS were examined. The CS was a series of 27 $2.8 \mathrm{kHz}$ pure tone pips (200 ms duration repeated at $0.9 \mathrm{~Hz}$ ). Eight hours after the initial fear learning, rats displayed robust freezing when they were exposed to the CS in a different context $\left(F_{(3,93)}=781.70, p<0.0001\right.$, repeated-measures ANOVA; HAB vs Post-FC, $p<0.05$, Newman-Keuls post-test; Fig. $1 B)$ and the conditioned fear diminished progressively over three extinction sessions (Fig. 1C). Reconditioning was conducted after CSevoked fear returned to preconditioning levels with three extinction sessions ( $\mathrm{HAB}$ vs Post-EX, $p>0.05$ ) and resulted in stronger fear responses compared with the initial fear learning (Post-FC vs Post-REFC, $p<0.05)$. In contrast, the 13 rats receiving unpaired CS-US presentations showed no evidence of CS-induced fear, except immediately after shock delivery $\left(F_{(3,36)}=0.83, p>0.5\right.$, repeated-measures ANOVA; $p>0.05$ for all pairs, NewmanKeuls post-test) (Fig. 1B).

\section{Electrophysiological characteristics of the LA neurons}

Only stable, high SNR LA neurons verified by principal component and correlation analysis were included in the data analysis (Fig. 2B-D). In total 188 LA neurons were analyzed, 114 from the conditioned group and 74 from the unpaired controls. Histological analysis revealed that recorded cells were located within the dorsal and ventral LA (Fig. 2A). Consistent with previous reports, the LA neurons displayed low spontaneous firing rates (Quirk et al., 1995; Paré and Collins, 2000; Repa et al., 2001). The average firing rate was $0.68 \mathrm{~Hz}$, ranging from 0.01 to $13 \mathrm{~Hz}$, and the averaged spike width (the time between the maximum and minimum peak) was $0.43 \mathrm{~ms}$, ranging from 0.12 to $0.75 \mathrm{~ms}$. In accordance with previous results (Quirk et al., 1995), the waveform width and firing rate were inversely correlated $(r=-0.48, p<$ 0.0001 , Pearson's correlation test) and most cells showed wide spike widths and low firing rates, consistent with the pyramidaltype projection neurons, which are prevalent in the LA (McDonald, 1982; Davis et al., 1994; Medina et al., 2002). The average basal firing rates were not different among the behavioral sessions $\left(F_{(5,565)}=1.64, p>0.1\right.$, repeated-measures ANOVA) (data not shown).

Forty five of 114 (39\%) neurons in the paired group and 22 of $74(30 \%)$ neurons in the unpaired controls were determined as CS responsive based on the averaged CS-evoked neural activities in all of the training sessions. These neurons displayed phasic responses to tone within $100 \mathrm{~ms}$ following pip onset (Fig. 2E), with an average onset response latency of $26.3 \pm 1.9 \mathrm{~ms}$ (paired group, $25.3 \pm 2.5 \mathrm{~ms}$; unpaired group, $29.1 \pm 2.7 \mathrm{~ms} ; p>0.1$, unpaired $t$ test). The pip-evoked excitation appeared reliably throughout the individual CS presentations of 27 individual pips, thus the responses were averaged to enhance SNR of CS responses as in previous studies (Rogan et al., 1997; Repa et al., 2001; Herry 
A

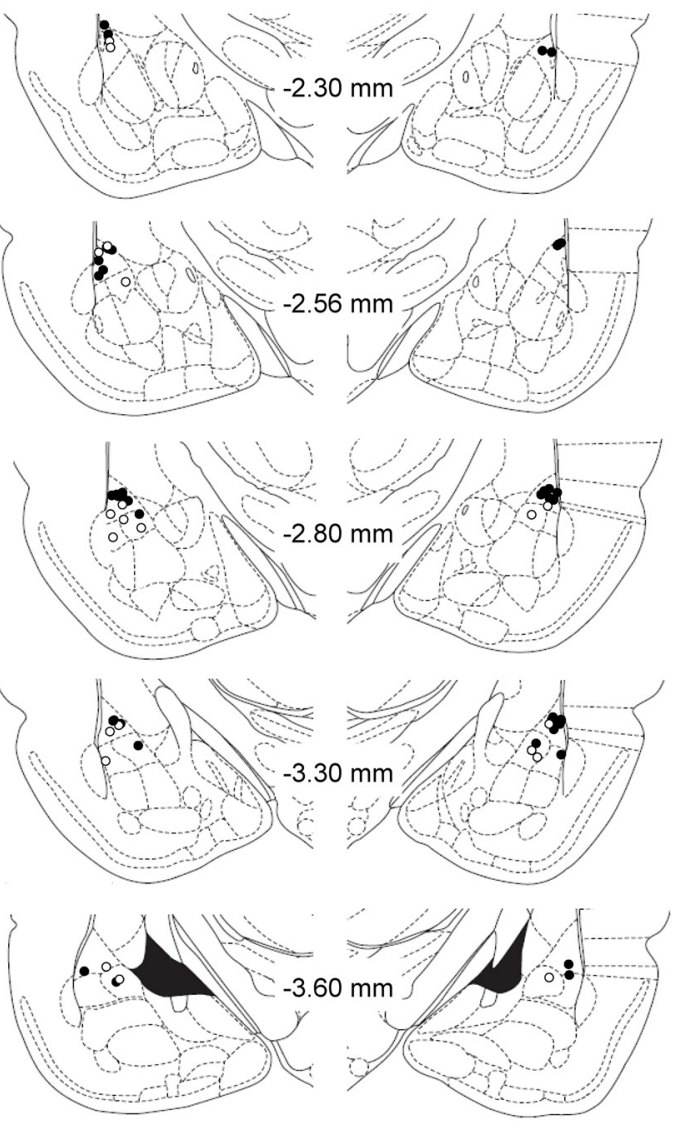

- Paired

- Unpaired
B

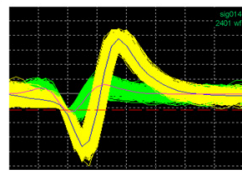

C

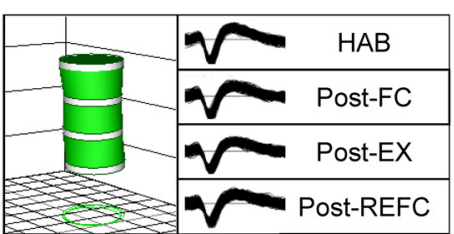

E

CS-onset responsive neuron

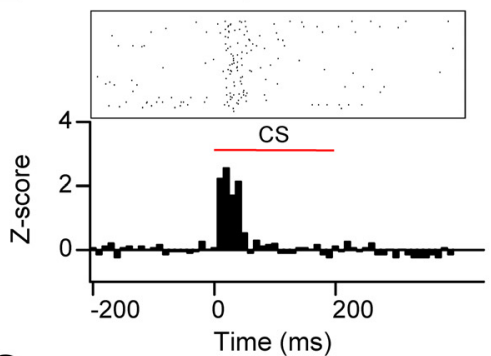

$\mathbf{G}$

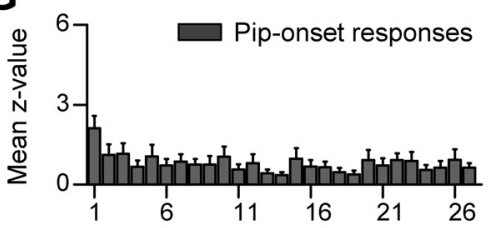

है

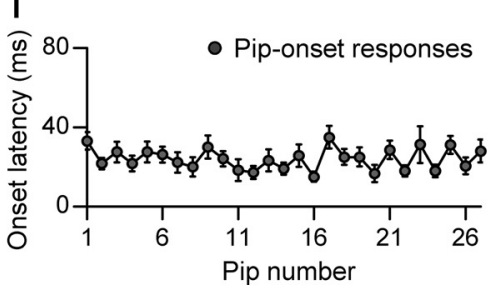

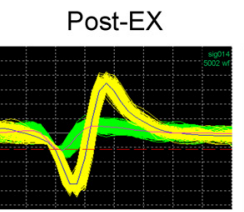

Post-REFC

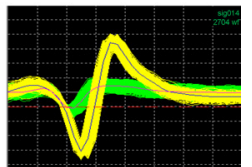

D

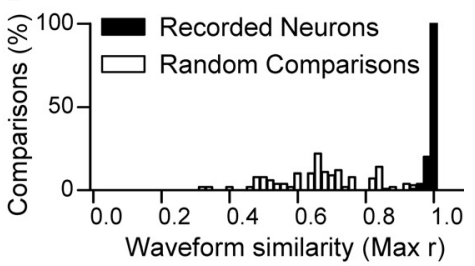

F CS-on \& offset responsive neuron

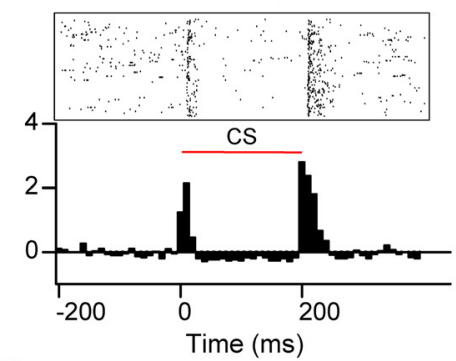

H
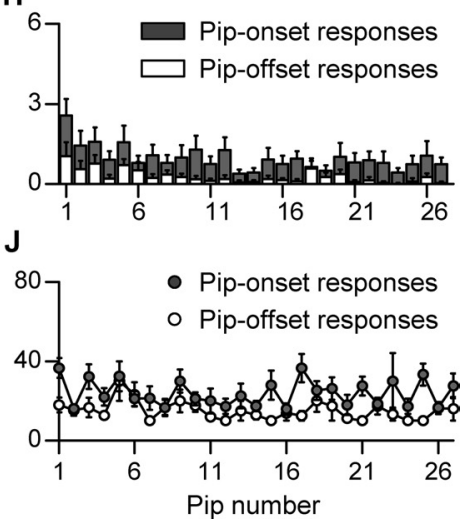

Figure 2. Long-term single-unit recordings in the LA. $\boldsymbol{A}$, Histological verification of the electrode placements in the paired group (filled circle) and the unpaired controls (open circle). $\boldsymbol{B}$, Representative waveforms of two neurons recorded from a single electrode and stably observed throughout the behavioral training period. Grid: $55 \mu \mathrm{V}$, $100 \mu \mathrm{S}$. C, Verification of long-term stable single-unit recordings using principal component space cylinders. A straight cylinder suggests that the same set of single units was recorded in different behavioral sessions. $\mathbf{D}, \mathbf{Q}$ uantitative evaluation of waveform similarity from units recorded on different days. Randomly selected waveforms were used as a control. $\boldsymbol{E}$, A representative unit showing phasic responses to $C S$ onset. $\boldsymbol{F}$, Both CS onset and CS offset induced strong excitation in a representative LA neuron. G, The amplitude of the pip-onset responses in the CS-onset responsive neurons ( $n=45$ of paired group) throughout 27 tone pips composing the CS. $\boldsymbol{H}$, The amplitude of pip-onset (gray) and pip-offset (white) responses in CS-onset and CS-offset responsive neurons ( $n=31$ of paired group). $\boldsymbol{I}$, Onset latencies of pip-onset responses in the CS-onset responsive neurons. J, Onset latencies of pip-onset and pip-offset responses in CS-onset and CS-offset responsive neurons.

Table 1. Basal firing rates and CS-response properties of the recorded LA neurons in the paired group $(n=114)$ and the unpaired controls $(n=74)$ throughout the reversible fear learning

\begin{tabular}{|c|c|c|c|c|c|c|c|c|c|c|c|c|c|c|c|}
\hline & \multicolumn{3}{|c|}{ All sessions averaged } & \multicolumn{3}{|l|}{ HAB } & \multicolumn{3}{|l|}{ Post-FC } & \multicolumn{3}{|l|}{ Post-EX } & \multicolumn{3}{|l|}{ Post-REFC } \\
\hline & \multirow[b]{2}{*}{ Firing rates $(\mathrm{Hz})$} & \multicolumn{2}{|c|}{$\begin{array}{l}\% \text { of responsive } \\
\text { cells }\end{array}$} & \multirow[b]{2}{*}{ Firing rates $(\mathrm{Hz})$} & \multicolumn{2}{|c|}{$\begin{array}{l}\% \text { of responsive } \\
\text { cells }\end{array}$} & \multirow[b]{2}{*}{ Firing rates $(\mathrm{Hz})$} & \multicolumn{2}{|c|}{$\begin{array}{l}\% \text { of responsive cells (newly } \\
\text { emerged) }\end{array}$} & \multirow[b]{2}{*}{ Firing rates $(\mathrm{Hz})$} & \multicolumn{2}{|c|}{$\begin{array}{l}\% \text { of responsive cells (newly } \\
\text { emerged) }\end{array}$} & \multirow[b]{2}{*}{ Firing rates $(\mathrm{Hz})$} & \multicolumn{2}{|c|}{$\begin{array}{l}\% \text { of responsive cells (newly } \\
\text { emerged) }\end{array}$} \\
\hline & & Onset & Offset & & Onset & Offset & & Onset & Offset & & Onset & Offset & & Onset & Offset \\
\hline Paired & $0.79 \pm 0.19$ & 39.47 & 27.19 & $0.89 \pm 0.21$ & 28.95 & 20.18 & $0.82 \pm 0.24$ & 34.21 (15.79) & 28.95 (18.42) & $0.85 \pm 0.22$ & $25.44(10.53)$ & $14.04(10.53)$ & $0.68 \pm 0.18$ & $29.83(13.16)$ & 21.05 (15.79) \\
\hline Unpaired & $0.52 \pm 0.21$ & 29.73 & 24.32 & $0.55 \pm 0.22$ & 25.68 & 12.16 & $0.55 \pm 0.22$ & $22.97(6.76)$ & $25.68(20.27)$ & $0.42 \pm 0.16$ & $18.92(8.11)$ & $6.76(4.05)$ & $0.50 \pm 0.22$ & $12.16(6.76)$ & 8.11 (8.11) \\
\hline
\end{tabular}

et al., 2008). Interestingly, the amplitude of pip-onset responses was relatively large at the first pip and remained stable for the remaining pips (Fig. $2 G$ ), and the response latencies were stable across the individual pips (Fig. 2I). The number of CS-responsive neurons in each separate session was not significantly changed throughout the course of reversible fear learning, while repeated unpairing resulted in fewer neurons being responsive (Table 1). Histological analysis revealed that LA dorsal (LAd) neurons responded to the CS with shorter response latencies than LA ventral (LAv) neurons (LAd, $24.3 \pm 2.1 \mathrm{~ms}$; LAv, $31.6 \pm 3.8 \mathrm{~ms} ; p<0.05$, unpaired $t$ test) (Bordi et al., 1993). Interestingly, $43 \%$ of the CS-onset responsive neurons $(n=29)$ also exhibited CS-offset 
responses (Fig. $2 F$ ), while 20 neurons were only responsive to CS offset with an average latency of $26.5 \pm 3.2 \mathrm{~ms}$. The amplitude of the pip-offset responses fluctuated within the CS presentation consisting of 27 tone pips (Fig. $2 \mathrm{H}$ ) and the response latencies were relatively stable across the individual pips (Fig. 2J).

\section{LA ensemble activity represents updated CS-US association strength in reversible fear learning}

It has been reported that fear conditioning increases the CSevoked responses of LA neurons, and that closely following extinction results in decreased tone responses in vivo (Quirk et al., 1995; Collins and Paré, 2000; Repa et al., 2001; Goosens et al., 2003). However, neural representations of fear memory involving extensive extinction and subsequent reconditioning have remained elusive, because most previous studies have used relatively short behavioral procedures spanning a day or two. Therefore, we investigated LA responses to the CS in reversible fear learning comprising extensive extinction and reconditioning. Conditioning-induced changes in tone-evoked firings were examined $8 \mathrm{~h}$ after the initial fear conditioning, a time at which fear memory is fully consolidated (Schafe and LeDoux, 2000; Schafe et al., 2000).

We constructed a population $z$-score PETH throughout reversible fear learning and found that LA neurons displayed potent excitation in response to CS-onset and their activity was dynamically modulated in reversible fear learning, corresponding to the CS-US association strength. Conditioning resulted in a strong CS-evoked excitation of LA neurons, while this excitation was weakened during extensive extinction, and reconditioning reinstated a strong CS response (Fig. $3 A$ ). In the unpaired controls, however, CS-evoked responses were largely unchanged by initial unpairing, and were weakened by the second unpairing.

The average CS-evoked responses of LA population were quantified as a mean $z$-value of $0-100 \mathrm{~ms}$ following CS-onset and compared across retention test sessions of reversible fear learning. Fear conditioning significantly increased the average CS response compared with habituation $\left(F_{(3,12)}=14.03, p<0.001\right.$, one-way ANOVA; HAB vs Post-FC, $p<0.05$, Newman-Keuls post-test), whereas unpairing did not alter LA neuronal responses $\left(F_{(3,12)}=3.52, p<0.05\right.$, one-way ANOVA; HAB vs Post-UP, $p>0.05$, Newman-Keuls post-test) (Fig. $3 B$ ). Three tone-alone extinction sessions resulted in decreased LA responses indiscernible with habituation (HAB vs Post-EX, $p>0.05$ ). These results are consistent with previous reports, which demonstrated the short-term effects of fear conditioning and extinction on LA neurons (Quirk et al., 1995; Repa et al., 2001) and further suggest that the updating of CS-US association strength that takes place during reversible fear learning is represented in the LA even after consolidation. Consistently, reconditioning again increased CS-evoked responses of the LA compared with both the Post-EX and the habituation session (Post-EX vs Post-REFC, $p<$ $0.05 ; \mathrm{HAB}$ vs Post-REFC, $p<0.05$ ). In the unpaired controls, LA neuronal responses to CS-onset slightly decreased after the second unpairing, possibly due to safety learning (Lolordo, 1969; Rogan et al., 2005), but not to statistical significance (Post-EX vs Post-UP2, $p>0.05$ ) (Fig. 3B). The average LA population signal was positively correlated with the freezing behavior in the paired group ( $r=0.55, p<0.001$, Pearson's correlation test), but not in the unpaired control $(r=0.08, p>0.1$, Pearson's correlation test) (Fig. 3C).

Importantly, CS-evoked response latencies were also reversibly altered; the CS-evoked response arose and peaked more rapidly following both of the conditioning sessions compared with the preceding sessions (onset response latencies, HAB vs PostFC, Post-FC vs Post-EX, Post-EX vs Post-REFC, $p<0.05$, paired $t$ test; peak response latencies, $p<0.05$ for the same pairs, paired $t$ test) (Fig. $3 D$ ). Again, unpaired controls did not exhibit significant changes $(p>0.1$ for the same pairs, paired $t$ test) (data not shown). Faster response latencies are consistent with strengthened influence from the short-latency thalamic pathway (McKernan and Shinnick-Gallagher, 1997; Quirk et al., 1997). These intricate, dynamic changes in the CS-response profile further support the involvement of specific plastic mechanisms reversibly recruited in our learning paradigm.

Additionally, we checked whether CS-offset responses were altered following reversible fear learning, because a similar number of LA neurons were responsive to CS-offset. Fear conditioning, however, did not significantly alter the CS-offset responses of the LA neurons and the responses disappeared following extensive extinction (Fig. $3 E-G$ ). Collectively, these results suggest that the average LA ensemble activity represents updated CS-US association strength in reversible fear learning and maintains this representation beyond memory consolidation, consistent with previous reports (Maren, 2000; Goosens et al., 2003; Hong et al., 2011).

\section{Distinct subpopulations of LA fear neurons represent the updated and original CS-US association strength in reversible fear learning}

It has been demonstrated that fear conditioning results in a strong elevation of CS-evoked LA field potentials (Rogan et al., 1997), while only 10-30\% of LA neurons display increased CSevoked responses after fear conditioning and this subset of neurons exhibit various types of learning-induced plasticity, such as transient or persistent potentiation by fear conditioning (Quirk et al., 1995; Repa et al., 2001). We thus further analyzed our data on a cell-by-cell basis to identify distinct LA neuronal subpopulations that encode the various facets of reversible fear learning. We focused on CS-onset responsive neurons, since the LA population displayed stronger excitation in response to CS onset and this response was dynamically modulated during reversible fear learning.

We first identified neurons displaying significant and increased responses to CS onset after either of the two conditioning sessions (Post-FC or Post-REFC) compared with the preceding sessions (HAB or Post-EX), and these neurons were defined as fear neurons ( $n=25,56 \%$ of CS-onset responsive units) (Fig. $4 A$ ). We also sought extinction neurons displaying increased CS responses only after extinction and found only one, consistent with previous results showing that they reside mostly in the BA (Herry et al., 2008). Sixty-eight percent of the fear neurons increased their responses to CS after the initial fear learning (conditioning-potentiated fear neurons, $n=17$ ) (Fig. $4 B$ ) and a larger number of neurons exhibited elevated responses following reconditioning (reconditioning-potentiated fear neurons, $n=$ $21,84 \%$ of fear neurons) (Fig. $4 C$ ). Both conditioning- and reconditioning-potentiated fear neurons displayed reversible changes of CS-evoked firing patterns throughout the course of reversible fear learning, while small and relatively constant responses were observed in the other CS-responsive neurons that were categorized as nonfear-encoding neurons (other neurons, $n=20$, 44\% of CS-onset responsive units) (Fig. $4 D$ ). The basal firing rates and spike duration of fear neurons were not different from the other CSresponsive neurons ( $p>0.1$, unpaired $t$ test) (Fig. $4 E$ ). However, fear neurons responded to the CS with a shorter response latency compared with the other neurons (fear neurons, $24.0 \pm 1.6 \mathrm{~ms}$; 


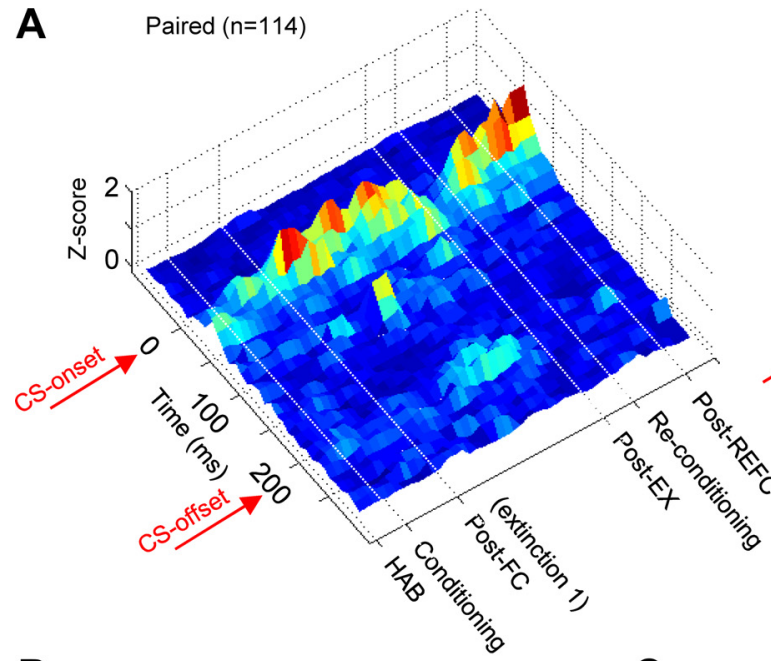

B CS-onset responses

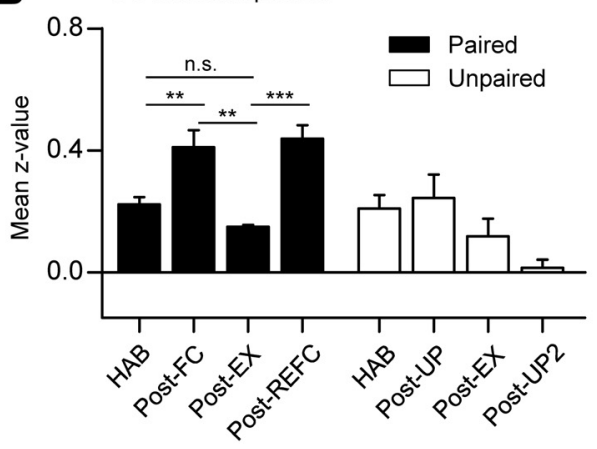

E

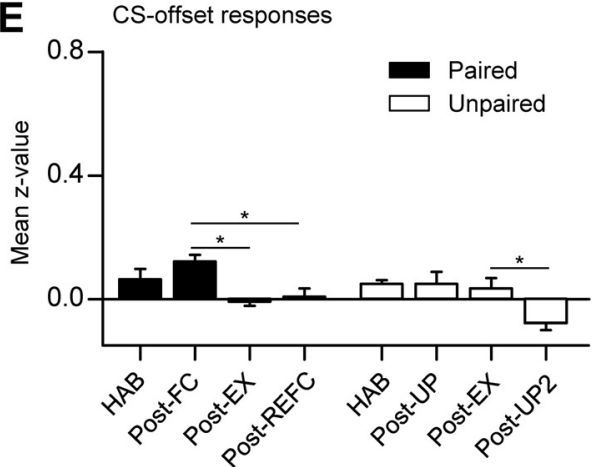

C

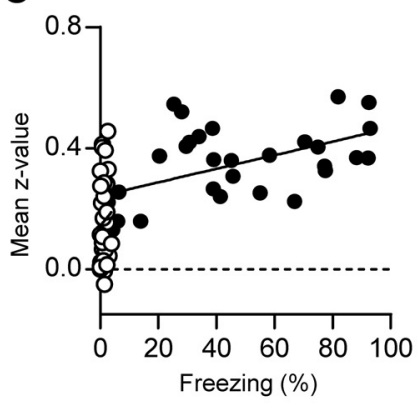

$\mathbf{F}$

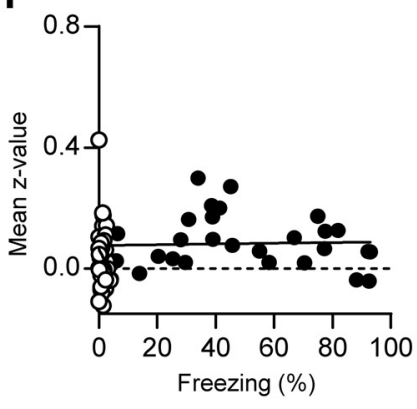

Unpaired $(n=74)$

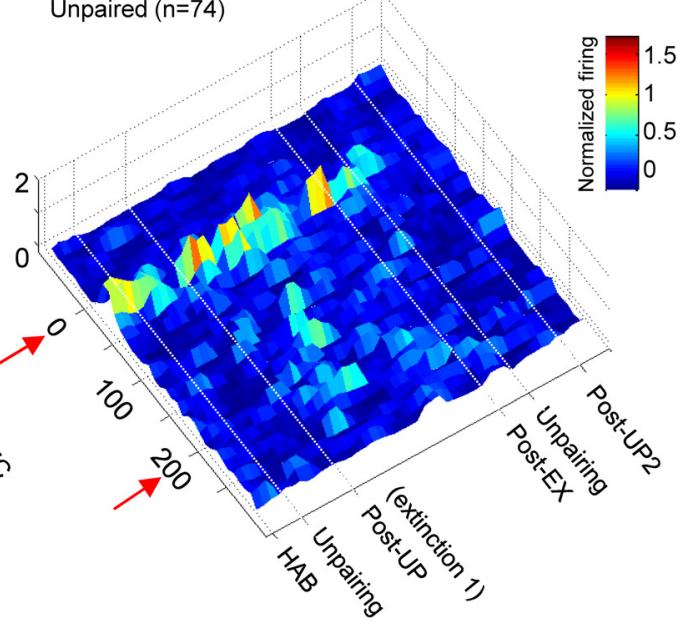

D

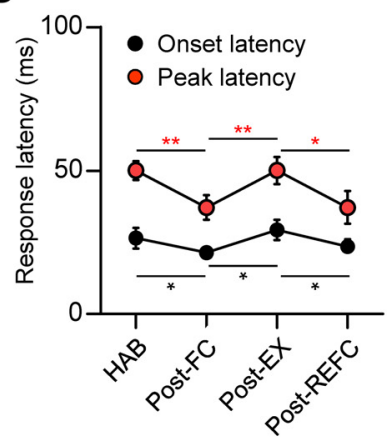

G

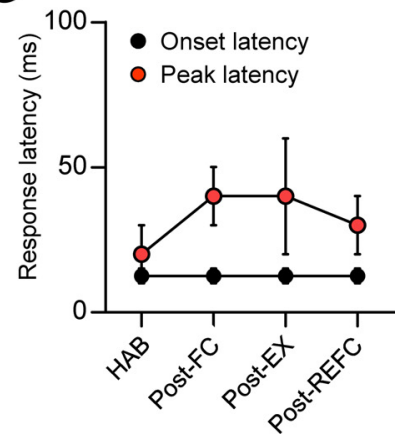

Figure 3. Average LAensemble activity represents the updated CS-US association strength in reversible fear learning.A, Populationz-score PETH throughout the behavioral training in the paired group $(n=$ 114 , left) and the unpaired controls $(n=74$, right). The surface plot of the normalized firing rate was calculated and was smoothed for \pm 1 trials. $\boldsymbol{B}$, Comparison of mean $z$-values calculated in a period of 0 - 100 ms following CS onset. The paired group displayed reversible CS-evoked responses in contrast to the unpaired controls. C, Correlation analysis between neural responses and freezing behavior. A significant correlation was observed only in the conditioned group ( $r=0.55$; filled circle), not in the unpaired controls $(r=0.08$; empty circle). $\boldsymbol{D}$, Comparison of the onset and peak response latency across the retention test sessions. Conditioning resulted in a more rapid onset and peak response latency compared with the preceding sessions. Error bars indicate SEM. E-G, The same analysis performed for the CS-offset responses. Fear conditioning did not significantly alter the CS-offset responses of the LA neurons. ${ }^{*} p<0.05$, ${ }^{* *} p<0.001,{ }^{* * *} p<0.0001$.

other neurons, $32.5 \pm 5.2 \mathrm{~ms} ; p<0.05$, unpaired $t$ test) (Fig. $4 F$ ) and were frequently found in the dorsal part of the LA, with a few in the ventral LA (Fig. 4G), suggesting potent innervation by short-latency sensory inputs. Interestingly, we found that there was a significant overlap between neurons that were potentiated after the original fear conditioning and reconditioning; reconditioning repotentiated $76 \%$ of the conditioning-potentiated fear neurons $(n=13)$ (Fig. $4 A)$, suggesting that traces of the initial fear learning remained even after extensive extinction, which allowed neurons to be readily recruited by the subsequent reconditioning.

To identify distinct LA neuronal subpopulations that encode various facets of reversible fear learning, we tracked the changes in CS-evoked firing of neurons that were potentiated following the initial fear learning (conditioning-potentiated fear neurons) in subsequent extinction and reconditioning. Although the averaged CS-evoked responses of conditioning-potentiated fear neurons appeared to exhibit reversible modulation (Fig. 4B), a cell-by-cell analysis revealed that this population was not homogeneous; two distinct classes of neurons were identified based on their responses to extinction (Fig. 5A). Half of the conditioningpotentiated neurons exhibited a significant loss of CS-evoked responses after extinction (extinction-susceptible fear neurons, $n=9,53 \%$ of conditioning-potentiated fear neurons) (Fig. $5 B$ ), while the other half was extinction-resistant (extinction-resistant fear neurons, $n=8,47 \%$ of conditioning-potentiated fear neurons) (Fig. $5 C$ ), retaining increased CS responses even after ex- 
A

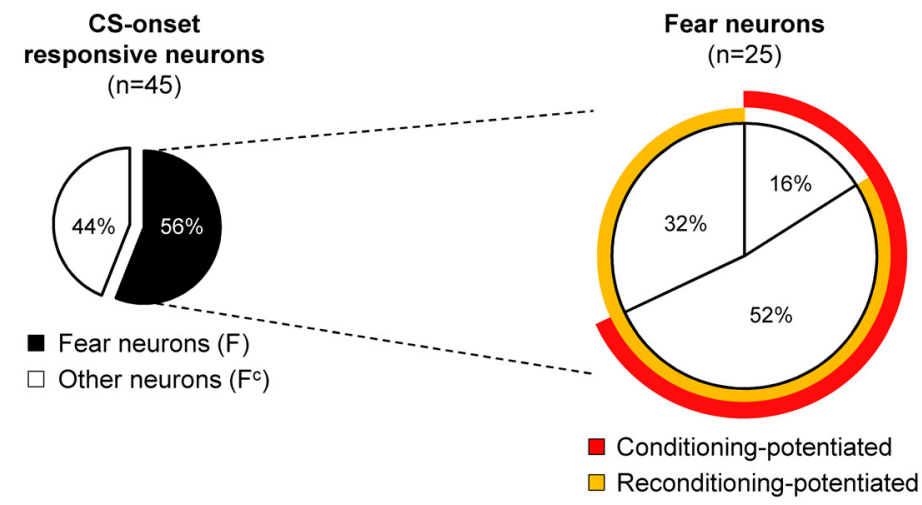

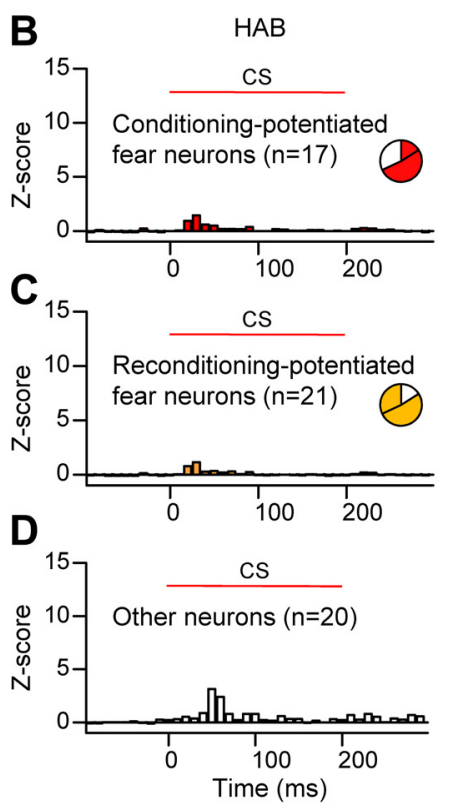

E

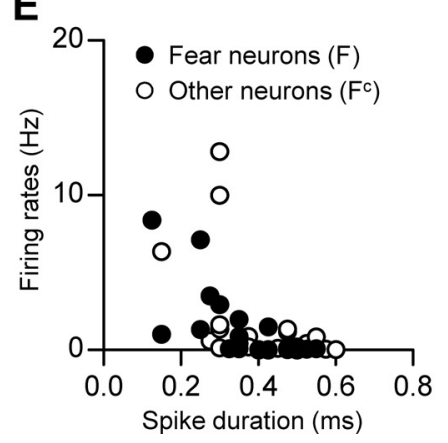

Post-FC
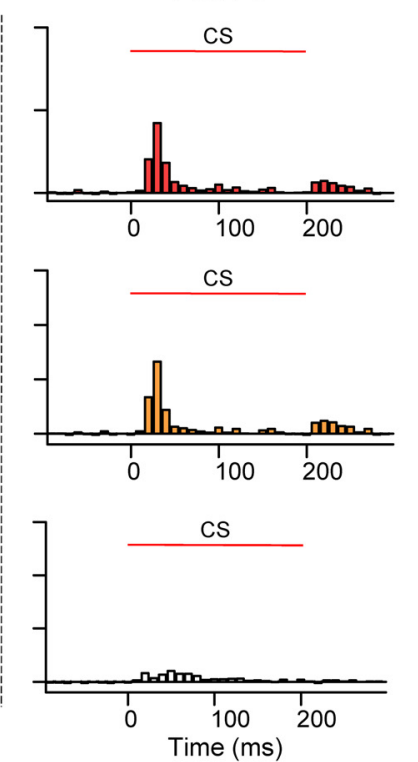

F

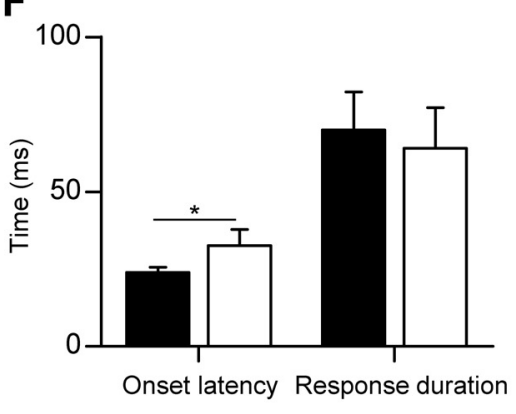

Post-EX

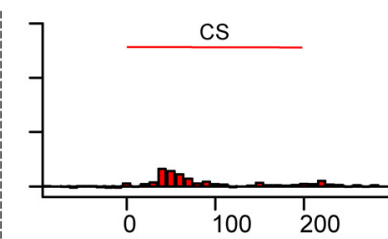

cS
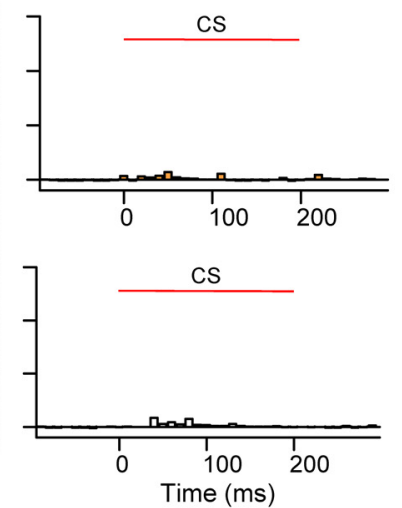

Post-REFC

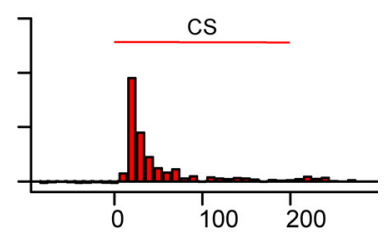

cs
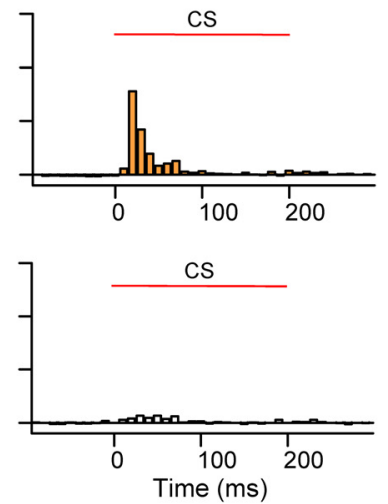

G

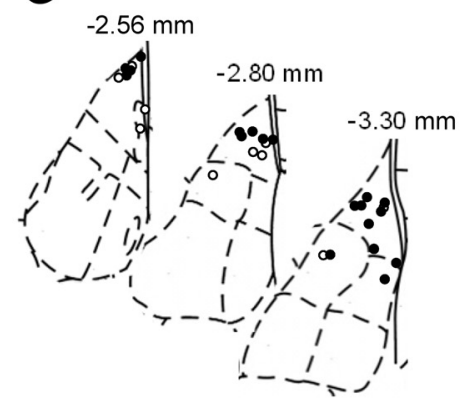

Figure 4. Fear-encoding neurons display potentiated CS-evoked responses following fear conditioning and reconditioning. $A$, Pie chart shows the percentage of fear neurons among the CS-onset responsive neurons (left) and the subcategories of fear neurons (right). A large overlap between the conditioning-potentiated and reconditioning-potentiated fear neurons was observed. $\boldsymbol{B}, Z$-score PETH of conditioning-potentiated fear neurons ( $n=17,68 \%$ of fear neurons). C, $Z$-score PETH of reconditioning-potentiated fear neurons ( $n=21,84 \%$ of fear neurons). D, Z-score PETH of (S-onset responsive, but not fear-encoding neurons (other neurons, $n=20,44 \%$ of (S-onset responsive units). $E$, The basal firing rates and spike duration of fear neurons were not different from other neurons. $F$, A comparison of onset latency and response duration. Fear neurons responded with a shorter latency to CS onset compared with the other neurons. Error bars indicate SEM. G, Histological analysis revealed that fear neurons were preferentially found in the $\operatorname{LAd} .{ }^{*} p<0.05$.

tensive extinction. These results are consistent with a previous study, which reported similar neuronal populations within a single extinction session conducted $1 \mathrm{~h}$ after fear conditioning (Repa et al., 2001). Interestingly, the extinction-susceptible fear neurons exhibited typical phasic and strong responses to CS onset corresponding to short-latency sensory inputs, whereas extinction-resistant fear neurons exhibited smaller but more sustained responses to the tone $(>100 \mathrm{~ms})$. The onset latencies were not different between these two populations (extinction-susceptible fear neurons, $20.0 \pm 2.9 \mathrm{~ms}$; extinction-resistant fear neurons, $22.5 \pm 3.1 \mathrm{~ms} ; p>0.1$, unpaired $t$ test) (Fig. 5E) and histological analysis confirmed that both neuronal populations were located in the dorsal part of the LA (Fig. 5G). However the CS-evoked responses of extinction-resistant fear neurons lasted much longer (extinctionsusceptible fear neurons, $45.6 \pm 16.1 \mathrm{~ms}$; extinction-resistant fear 
A

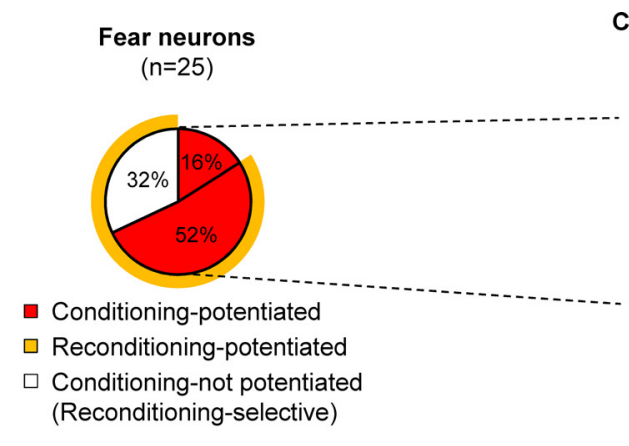

Conditioning-potentiated

fear neurons

$(n=17)$

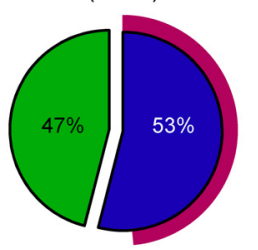

EX-resistant

- EX-susceptible

Reversible fear neurons (R)
B
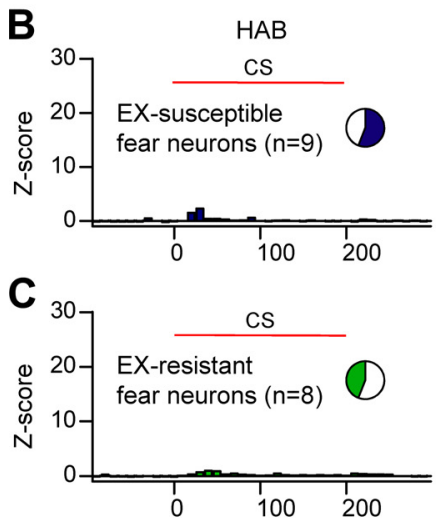

D

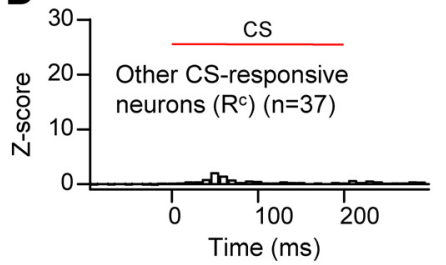

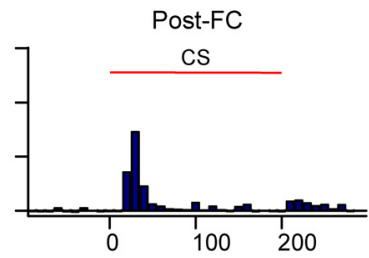
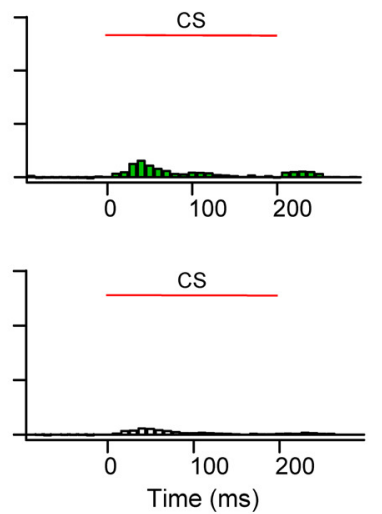

Post-EX

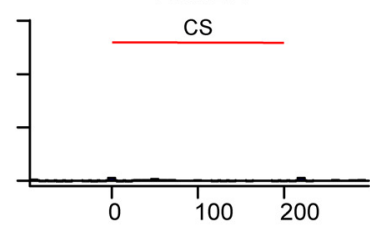

CS
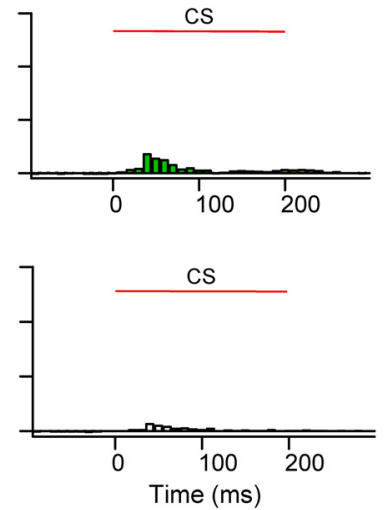
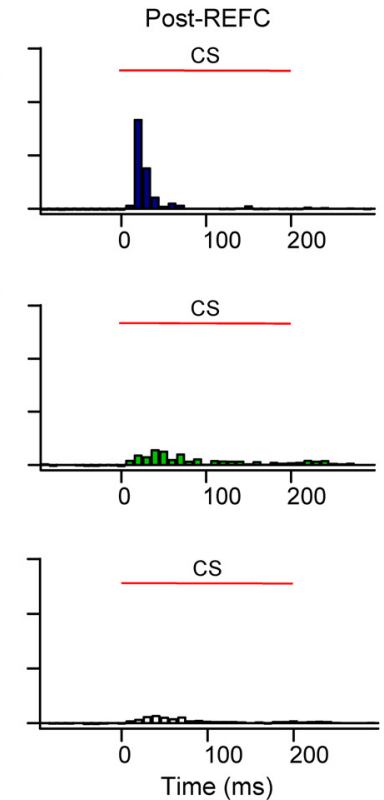

E

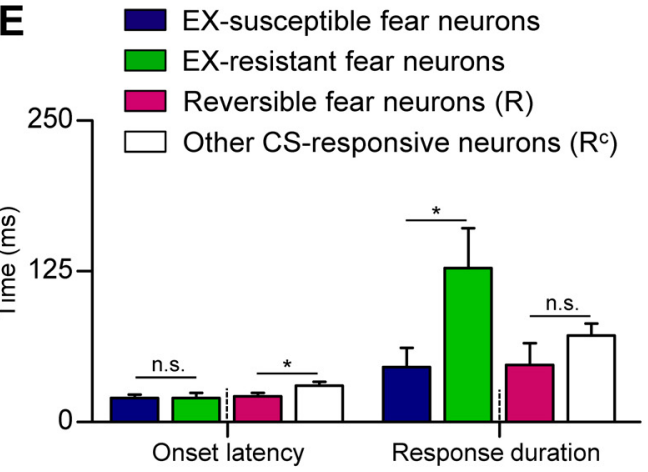

$\mathbf{F}$

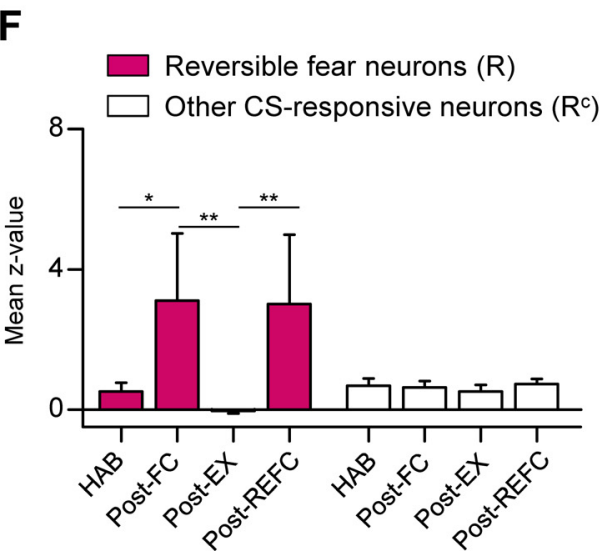

G

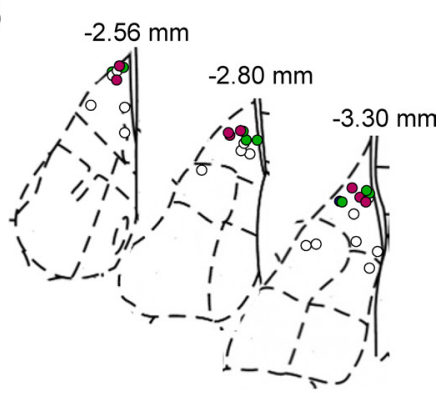

Figure 5. Subpopulations of fear neurons display distinct encoding of extinction and reconditioning. $A$, Pie chart summarizes how the subcategories of conditioning-potentiated fear neurons responded to subsequent extinction and reconditioning. The left pie chart represents identical fear neurons as those in Figure $4 A$. B, Z-score PETH of extinction-susceptible fear neurons $(n=9,53 \%$ of conditioning-potentiated fear neurons). These fear neurons displayed decreased responses after extinction and repotentiated responses after reconditioning. $C S$ responses of reversible fear neurons displayed the same reversible trend. C, Z-score PETH of extinction-resistant fear neurons ( $n=8,47 \%$ of conditioning-potentiated fear neurons), which retained increased CS responses after extensive extinction. $\boldsymbol{D}, Z$-score PETH of other CS-responsive neurons $(n=37)$ that were not categorized as reversible fear neurons. $\boldsymbol{E}$, Comparison of onset response latency and response duration. Extinction-resistant fear neurons displayed sustained responses compared with extinction-susceptible fear neurons. The response latency of the reversible fear neurons was shorter than the other CS-responsive neurons. $\boldsymbol{F}$, The mean $z$-value comparisons of reversible fear neurons and the other CS-responsive neurons. Error bars indicate SEM. $\boldsymbol{G}$, Histological analysis confirmed that conditioning-potentiated fear neurons, including reversible fear neurons, were preferentially located in the dorsal part of the LA. ${ }^{*} p<0.05,{ }^{* *} p<0.001$.

neurons, $111.3 \pm 21.9 \mathrm{~ms} ; p<0.05$, unpaired $t$ test) (Fig. $5 E$ ), and were weaker (mean $z$-value, extinction-susceptible fear neurons, $9.9 \pm 2.1$; extinction-resistant fear neurons, $3.5 \pm 0.4 ; p<0.005$, unpaired $t$ test; data not shown), suggesting distinct connectivity. The longer, persistent responses in the extinction-resistant fear neurons may involve multisynaptic local sensory inputs and/or innervations from cortical regions (Repa et al., 2001), and may represent the persistence of memory after extinction.

Importantly, extinction-susceptible and extinction-resistant neurons were also distinguished by CS-evoked activity after 

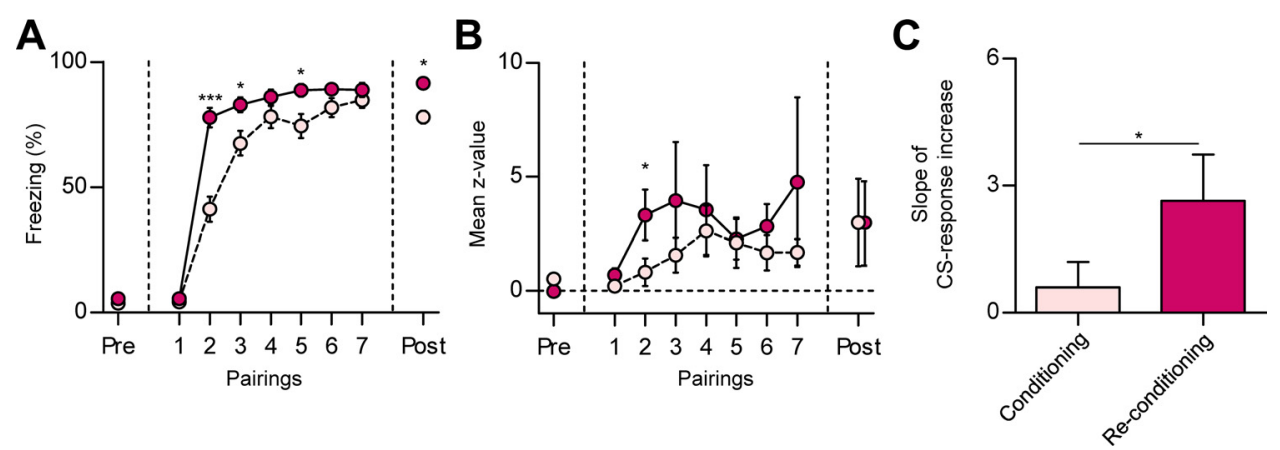

Figure 6. The neural correlates of savings after extinction. $\boldsymbol{A}$, Behavioral evidence of savings. Reconditioning occurred faster than the initial fear learning. $\boldsymbol{B}$, The mean $z$-values of reversible fear neurons. CS-evoked responses were larger and rapidly increased during reconditioning (conditioning, pink circle; reconditioning, red circle). C, Comparison of the slope of CS-response increase between the first and second pairings. Error bars indicate SEM. ${ }^{*} p<0.05,{ }^{* * *} p<0.0001$.

reconditioning. The average CS-evoked responses of extinctionsusceptible fear neurons were strongly potentiated after reconditioning, resembling LA ensemble activity (Fig. 5B), whereas extinction-resistant fear neurons did not exhibit further increases after reconditioning (Fig. 5C). Intriguingly, a cell-by-cell analysis revealed that all of the extinction-susceptible fear neurons but for a single exception showed increased and significant responses after reconditioning, and thus comprise a subpopulation encoding reversible changes in CS-US association strength during dynamic fear learning (reversible fear neurons, $n=8,89 \%$ of extinction-susceptible fear neurons, and $47 \%$ of conditioningpotentiated fear neurons) (Fig. 5A). In contrast, all of the other CS-responsive neurons (other CS-responsive neurons, $n=37$ ) (Fig. 5E) displayed weak, constant CS-evoked responses. We compared the mean $z$-values of the reversible fear neurons across sessions and found that their responses were reversibly altered in a manner similar to LA population ensemble activity, but to a greater extent $(p<0.001$, Friedman test; HAB vs Post-FC, Post-FC vs Post-EX, Post-EX vs Post-REFC, $p<0.05$, Dunn's post-test). In contrast, the mean $z$-values of the other CSresponsive neurons remained constant $(p>0.05$, Friedman test; $p>0.05$ for the same pairs, Dunn's post-test; Fig. $5 F$ ), suggesting the reversible fear neurons lead the LA ensemble activity in the process of reversible fear learning. Reversible fear neurons displayed a shorter response latency compared with the other CS-responsive neurons (reversible fear neurons, $18.8 \pm 3.0 \mathrm{~ms}$; other CS-responsive neurons, $30.3 \pm 3.1$ ms; $p<0.05$, unpaired $t$ test), but with a similar response duration (reversible fear neurons, $47.5 \pm 18.1 \mathrm{~ms}$; other CSresponsive neurons, $71.9 \pm 10.0 \mathrm{~ms} ; p>0.1$, unpaired $t$ test) (Fig. 5E). Consistent with these electrophysiological characteristics, histological analysis revealed that reversible fear neurons were preferentially located in the dorsal part of the LAd (Fig. 5G), which is known to receive dense thalamic shortlatency innervations (LeDoux et al., 1990; Quirk et al., 1997). Together, these results suggest there are two distinct subpopulations of fear-encoding neurons in the LA; one is dynamically regulated by fear conditioning and extinction while the other represents persistent fear memory.

\section{Reversible fear neurons represent savings effect after extinction}

The relearning of fear occurs much faster than original fear learning, even after extensive extinction, and this phenomenon is known as the savings effect (Kehoe, 1988; Macrae and Kehoe, 1999; Rescorla, 2001). Although savings has been widely sug- gested as empirical evidence of memory persistence after extinction (Macrae and Kehoe, 1999; Bouton, 2002), the neural correlates of savings have yet to be identified.

In accordance with previous reports (Rescorla, 2001), we found that the freezing responses progressively increased during the initial fear learning, but increased more rapidly during reconditioning. CS-evoked freezing was indistinguishable between preconditioning sessions, HAB and Post-EX ( $p>0.05$, paired $t$ test), and at the first pairing of the two conditioning sessions ( $p>$ 0.1 , paired $t$ test). However, the discrepancy between the learning curves of fear conditioning and reconditioning was significant at the second CS-US pairing ( $p<0.0001$, paired $t$ test), the third pairing ( $p<0.005$, paired $t$ test), and the fifth pairing $(p<0.005$, paired $t$ test) (Fig. 6A). Although the difference in conditioned freezing disappeared by the end of the conditioning sessions ( $p>$ 0.1 , paired $t$ test), stronger freezing was also observed in the retention test of reconditioning ( $p<0.0001$, paired $t$ test) compared with the initial conditioning.

Interestingly, the CS-evoked responses of the reversible fear neurons increased more rapidly during reconditioning, in tight correlation with the behavioral results. The mean $z$-values in the two conditioning sessions diverged at the second CS-US pairing $(p<0.05$, paired $t$ test) (Fig. 6B), while the CS-responses in the preconditioning sessions and at the first pairing were not significantly different. The statistical difference disappeared at the third pairing ( $p>0.1$, paired $t$ test), suggesting that the potentiation of the neural responses reached a ceiling faster than the behavioral responses. The rapid increases during the reconditioning session were further confirmed by comparison of the slope of CS-response increase between the first and second CS-US pairings ( $p<0.05$, paired $t$ test) (Fig. $6 C$ ). These results suggest that reversible fear neurons not only integrate the reversible changes in association strength, but also are primed by prior learning-induced changes so as to detect a given CS-US association more rapidly during subsequent relearning. The persistently potentiated CS responses of extinction-resistant fear neurons may also trigger/support this rapid repotentiation of the CS responses observed in reversible fear neurons. In addition to the more rapid in-session learning upon reconditioning, stronger freezing was also observed in the retention test of reconditioning $(p<0.0001$, paired $t$ test) compared with the initial conditioning, which is likely to be supported by the larger number of neurons recruited by reconditioning (Fig. 4A) compared with the initial fear learning. 


\section{Discussion}

LA neurons were found to reversibly encode updated CS-US association strength throughout the course of sequential learning. The LA neuronal population displayed increased average CS-evoked firing after conditioning, decreased responses after extinction, and repotentiated responses after reconditioning, in tight correlation with the changes in the freezing responses. Cellby-cell analysis revealed the two distinct subpopulations of fearencoding neurons in the LA; one exhibited reversible encoding of fear learning that corresponded to the LA population firing (reversible fear neurons), whereas the other was resistant to change during extinction and reconditioning (extinction-resistant fear neurons), likely supporting the persistence of fear memory. Interestingly, reversible fear neurons exhibited both a stronger and more rapid acquisition of CS-US association during reconditioning relative to the initial conditioning, providing a neural representation of the savings effect during reconditioning.

The reversible fear neurons observed in the present study exhibit remarkably similar characteristics to distinct BA neurons that are responsive to fear conditioning, extinction, and renewal in a reversible manner and also a subset of LA neurons encoding the renewal of extinguished fear (Hobin et al., 2003; Herry et al., 2008). Since LA excitatory neurons are known to drive the activation of the central amygdala and fear expression via BA excitatory neurons (LeDoux, 2000; Pape and Pare, 2010; Amir et al., 2011), it is possible that the subset of LA neurons that responds to renewal (Hobin et al., 2003) largely overlaps with the reversible fear neurons identified here and that both preferentially innervate fear neurons of the BA (Herry et al., 2008), thus controlling CeM activity and contributing to reversible fear expression. Alternatively, reversible LA neuronal firing may alter activity of the amygdala-intercalated neurons and inhibitory CeL neurons that tonically inhibit the major projection neurons in the CeM (Paré et al., 2004; Amano et al., 2010; Haubensak et al., 2010). The extraordinary plasticity of these reversible fear neurons over the course of several days suggests that LA neural circuits can be dynamically modified even after memory consolidation.

The extinction-resistant fear neurons found in our study provide a neural substrate for the persistent fear memory trace, which had been predicted earlier (Pavlov, 1927; Pearce and Hall, 1980; Bouton and King, 1983). These neurons displayed CS responses of longer duration (Fig. 5), suggesting the influence of cortical regions where traces of persistent fear have also been identified (Corcoran and Quirk, 2007; Burgos-Robles et al., 2009; Sacco and Sacchetti, 2010; Sotres-Bayon and Quirk, 2010). The persistent potentiated firing of the extinction-resistant fear neurons may contribute to the relapse or spontaneous recovery of fear even after extensive extinction. Despite the persistent fear encoding in these neurons, after extinction, the expression of fearful responses is likely to be inhibited downstream of the LA (Ehrlich et al., 2009; Pape and Pare, 2010; Maren, 2011). Well known inhibitory mechanisms involving the prefrontal cortex (Milad and Quirk, 2002; Rosenkranz et al., 2003; Likhtik et al., 2005; Sotres-Bayon et al., 2006; Quirk and Mueller, 2008) and amygdala intercalated neurons (Chhatwal et al., 2005; Likhtik et al., 2008; Ehrlich et al., 2009) may provide inhibition at the BA or CeM leading to the suppression of fear responses. The contextdependent disinhibition of these subnuclei and the LA are believed to underlie fear memory relapse (Hobin et al., 2003; Likhtik et al., 2008; Ehrlich et al., 2009).

Extinction is thought to involve both inhibition and unlearning of original associations (Rescorla and Wagner, 1972; Bouton,
2002). The relative contribution of new learning and unlearning in the behavioral extinction of many forms of associative memory has been a key issue in memory research (Medina et al., 2002; Barad, 2006). In previous studies involving different learning paradigms, the immediate reversal of CS-US contingencies resulted in the reversal of neuronal responses in a subset of amygdala neurons (Schoenbaum et al., 1999; Paton et al., 2006). Consistent with these findings, our results in auditory cued-fear conditioning demonstrate that the CS responses of some LA neurons are suppressed after extinction and exhibit savings during relearning, but there are other neurons that exhibit persistent potentiation after extinction, suggesting that unlearning and new learning are both integrated at the level of the LA neurons. Consistent with previous reports (Repa et al., 2001), extinctionresistant fear neurons retained potentiated CS responses even after extensive extinction, while extinction-susceptible fear neurons showed a clear decrease in CS responses (Fig. 5). Together, this resulted in a net reduction of the LA ensemble activity after extensive extinction. Although the net CS response after extinction was indiscernible from baseline habituation responses, individual neurons displayed different responses, suggesting that network changes in LA connectivity upon fear conditioning persist after extinction. Because early and late extinction (within and beyond $6 \mathrm{~h}$ postconditioning, respectively) involve different mechanisms and lead to different neural changes (Maren and Chang, 2006; Myers et al., 2006; Chang et al., 2009), and most earlier recordings were limited to early extinction paradigms, our results constitute important evidence for the mechanisms recruited by late extinction.

Reconditioning after extinction has been less well explored, although the rapid reacquisition of fear has been regarded as proof of the persistence of memory after extinction (Bouton, 2002). Our findings show that whereas extinction does not return the network changes in LA connectivity to the preconditioning state, reconditioning appears to return the system to the preextinction state. Reconditioning resulted in an increase of the LA ensemble activity, which had decreased to baseline levels after extinction (Fig. 3), suggesting that LA neurons are able to adaptively represent updated CS-US association strength throughout the course of reversible fear learning. This repotentiation was supported by a majority of the conditioning-potentiated fear neurons, demonstrating a significant overlap of fear-encoding neurons. This overlap is accounted for the extinction-induced inhibitory mechanisms that temporarily suppress CS responses. Interestingly, the CS responses of reversible fear neurons appeared to be more readily potentiated upon reconditioning compared with the initial fear learning (Fig. 6), supporting the hypothesis that reconditioning reverses extinction-induced network changes. Together, these results suggest the conditioninginduced plasticity was temporarily inhibited by extinction and reconditioning eliminated this inhibition (Bouton and King, 1983; Quirk et al., 2006; Myers and Davis, 2007).

The strong reversible encoding of CS-US association strength in reversible fear neurons (Fig. 5) dominates the LA population coding (Fig. 3), suggesting that it is the plasticity of these neurons that is detected using field potential (Rogan et al., 1997) or immediate-early gene methods (Hall et al., 2001; Han et al., 2007; Reijmers et al., 2007). These fear neurons amount to only $10 \sim 30 \%$ of all the LA neurons, suggesting a rather sparse and restricted encoding of CS-US associations (Quirk et al., 1995; Repa et al., 2001; Han et al., 2007). In contrast, fear learninginduced synaptic potentiation has been observed in the general population of LA neurons (McKernan and Shinnick-Gallagher, 
1997; Kim et al., 2007; Zhou et al., 2009), leading to the previously suggested possibility that the majority of LA neurons are strongly inhibited by GABAergic interneurons (Paré and Gaudreau, 1996) and are thus virtually undetectable by either in vivo recordings or immediate-early gene staining methods. Interestingly, a previous report demonstrated that targeted ablation of the $\sim 15 \%$ of LA neurons that preferentially participated in learning can significantly impair auditory fear memory, whereas ablating a similarly sized random population had no effect (Han et al., 2009). It is tempting to hypothesize the similarly sized reversible fear neuron population in our recordings largely overlaps with the population targeted in these studies.

Traces of persistent fear memory have been suggested to reside in cortical regions (Corcoran and Quirk, 2007; BurgosRobles et al., 2009; Sacco and Sacchetti, 2010; Sotres-Bayon and Quirk, 2010), but how they may interact with the LA and support later savings or memory relapse has been largely unknown. Our findings show a strong neural correlate of savings in fearencoding LA neurons, which may be innervated and influenced by memory-preserving cortical regions to allow the more rapid detection of changes in CS-US association. Metaplastic mechanisms that enable more rapid synaptic plasticity at input synapses may also support the enhanced potentiation of CS responses in these neurons (Abraham, 2008). Extinction-resistant fear neurons, which were potentiated after the initial fear conditioning and retained the potentiation even after extensive extinction, may also play an important role in the persistence of fear memory and relapse after extinction.

Fear conditioning and extinction have served as primary models for the treatment of post-traumatic stress disorder (PTSD) and other anxiety disorders. Although most PTSD research aimed at thwarting the relapse of fear memory has focused on the dysfunctions or manipulations of the prefrontal cortex (Quirk et al., 2006; Sotres-Bayon et al., 2006), our research suggests that a component of persistent fear memory lies in the LA, thus providing an alternative target for clinical treatment.

\section{References}

Abraham WC (2008) Metaplasticity: tuning synapses and networks for plasticity. Nat Rev Neurosci 9:387. CrossRef Medline

Amano T, Unal CT, Paré D (2010) Synaptic correlates of fear extinction in the amygdala. Nat Neurosci 13:489-494. CrossRef Medline

Amir A, Amano T, Pare D (2011) Physiological identification and infralimbic responsiveness of rat intercalated amygdala neurons. J Neurophysiol 105:3054-3066. CrossRef Medline

Barad M (2006) Is extinction of fear erasure or inhibition? Why both, of course. Learn Mem 13:108-109. CrossRef Medline

Blair HT, Schafe GE, Bauer EP, Rodrigues SM, LeDoux JE (2001) Synaptic plasticity in the lateral amygdala: a cellular hypothesis of fear conditioning. Learn Mem 8:229-242. CrossRef Medline

Bordi F, LeDoux J, Clugnet MC, Pavlides C (1993) Single-unit activity in the lateral nucleus of the amygdala and overlying areas of the striatum in freely behaving rats: rates, discharge patterns, and responses to acoustic stimuli. Behav Neurosci 107:757-769. CrossRef Medline

Bouton ME (2002) Context, ambiguity, and unlearning: sources of relapse after behavioral extinction. Biol Psychiatry 52:976-986. CrossRef Medline

Bouton ME, King DA (1983) Contextual control of the extinction of conditioned fear: tests for the associative value of the context. J Exp Psychol Anim Behav Process 9:248-265. CrossRef Medline

Burgos-Robles A, Vidal-Gonzalez I, Quirk GJ (2009) Sustained conditioned responses in prelimbic prefrontal neurons are correlated with fear expression and extinction failure. J Neurosci 29:8474-8482. CrossRef Medline

Chang CH, Knapska E, Orsini CA, Rabinak CA, Zimmerman JM, Maren S (2009) Fear extinction in rodents. Curr Protoc Neurosci Chapter 8:Unit8 23. Medline

Chhatwal JP, Myers KM, Ressler KJ, Davis M (2005) Regulation of gephyrin and GABAA receptor binding within the amygdala after fear acquisition and extinction. J Neurosci 25:502-506. CrossRef Medline

Collins DR, Paré D (2000) Differential fear conditioning induces reciprocal changes in the sensory responses of lateral amygdala neurons to the CS(+) and CS(-). Learn Mem 7:97-103. CrossRef Medline

Corcoran KA, Quirk GJ (2007) Activity in prelimbic cortex is necessary for the expression of learned, but not innate, fears. J Neurosci 27:840-844. CrossRef Medline

Dalton GL, Wang YT, Floresco SB, Phillips AG (2008) Disruption of AMPA receptor endocytosis impairs the extinction, but not acquisition of learned fear. Neuropsychopharmacology 33:2416-2426. CrossRef Medline

Davis M (1992) The role of the amygdala in fear and anxiety. Annu Rev Neurosci 15:353-375. CrossRef Medline

Davis M, Whalen PJ (2001) The amygdala: vigilance and emotion. Mol Psychiatry 6:13-34. CrossRef Medline

Davis M, Rainnie D, Cassell M (1994) Neurotransmission in the rat amygdala related to fear and anxiety. Trends Neurosci 17:208-214. CrossRef Medline

Duclos Y, Schmied A, Burle B, Burnet H, Rossi-Durand C (2008) Anticipatory changes in human motoneuron discharge patterns during motor preparation. J Physiol 586:1017-1028. Medline

Ehrlich I, Humeau Y, Grenier F, Ciocchi S, Herry C, Lüthi A (2009) Amygdala inhibitory circuits and the control of fear memory. Neuron 62:757-771. CrossRef Medline

Falls WA, Miserendino MJ, Davis M (1992) Extinction of fear-potentiated startle: blockade by infusion of an NMDA antagonist into the amygdala. J Neurosci 12:854-863. Medline

Goosens KA, Hobin JA, Maren S (2003) Auditory-evoked spike firing in the lateral amygdala and Pavlovian fear conditioning: mnemonic code or fear bias? Neuron 40:1013-1022. CrossRef Medline

Hall J, Thomas KL, Everitt BJ (2001) Cellular imaging of zif268 expression in the hippocampus and amygdala during contextual and cued fear memory retrieval: selective activation of hippocampal CA1 neurons during the recall of contextual memories. J Neurosci 21:2186-2193. Medline

Han JH, Kushner SA, Yiu AP, Cole CJ, Matynia A, Brown RA, Neve RL, Guzowski JF, Silva AJ, Josselyn SA (2007) Neuronal competition and selection during memory formation. Science 316:457-460. CrossRef Medline

Han JH, Kushner SA, Yiu AP, Hsiang HL, Buch T, Waisman A, Bontempi B, Neve RL, Frankland PW, Josselyn SA (2009) Selective erasure of a fear memory. Science 323:1492-1496. CrossRef Medline

Haubensak W, Kunwar PS, Cai H, Ciocchi S, Wall NR, Ponnusamy R, Biag J, Dong HW, Deisseroth K, Callaway EM, Fanselow MS, Lüthi A, Anderson DJ (2010) Genetic dissection of an amygdala microcircuit that gates conditioned fear. Nature 468:270-276. CrossRef Medline

Herry C, Ciocchi S, Senn V, Demmou L, Müller C, Lüthi A (2008) Switching on and off fear by distinct neuronal circuits. Nature 454:600-606. CrossRef Medline

Hobin JA, Goosens KA, Maren S (2003) Context-dependent neuronal activity in the lateral amygdala represents fear memories after extinction. J Neurosci 23:8410-8416. Medline

Hong I, Song B, Lee S, Kim J, Kim J, Choi S (2009) Extinction of cued fear memory involves a distinct form of depotentiation at cortical input synapses onto the lateral amygdala. Eur J Neurosci 30:2089-2099. CrossRef Medline

Hong I, Kim J, Lee J, Park S, Song B, Kim J, An B, Park K, Lee HW, Lee S, Kim H, Park SH, Eom KD, Lee S, Choi S (2011) Reversible plasticity of fear memory-encoding amygdala synaptic circuits even after fear memory consolidation. PLoS One 6:e24260. CrossRef Medline

Jackson A, Fetz EE (2007) Compact movable microwire array for long-term chronic unit recording in cerebral cortex of primates. J Neurophysiol 98:3109-3118. CrossRef Medline

Kehoe EJ (1988) A layered network model of associative learning: learning to learn and configuration. Psychol Rev 95:411-433. CrossRef Medline

Kim J, Lee S, Park K, Hong I, Song B, Son G, Park H, Kim WR, Park E, Choe HK, Kim H, Lee C, Sun W, Kim K, Shin KS, Choi S (2007) Amygdala depotentiation and fear extinction. Proc Natl Acad Sci U S A 104:2095520960. CrossRef Medline

Kim J, Song B, Hong I, Kim J, Lee J, Park S, Eom JY, Lee CJ, Lee S, Choi S (2010) Reactivation of fear memory renders consolidated amygdala synapses labile. J Neurosci 30:9631-9640. Medline 
LeDoux JE (2000) Emotion circuits in the brain. Annu Rev Neurosci 23: 155-184. CrossRef Medline

LeDoux JE, Farb C, Ruggiero DA (1990) Topographic organization of neurons in the acoustic thalamus that project to the amygdala. J Neurosci 10:1043-1054. Medline

Likhtik E, Pelletier JG, Paz R, Par é D (2005) Prefrontal control of the amygdala. J Neurosci 25:7429-7437. CrossRef Medline

Likhtik E, Popa D, Apergis-Schoute J, Fidacaro GA, Par é D (2008) Amygdala intercalated neurons are required for expression of fear extinction. Nature 454:642-645. CrossRef Medline

Lin HC, Mao SC, Gean PW (2009) Block of gamma-aminobutyric acid-A receptor insertion in the amygdala impairs extinction of conditioned fear. Biol Psychiatry 66:665-673. CrossRef Medline

Lolordo VM (1969) Positive conditioned reinforcement from aversive situations. Psychol Bull 72:193-203. CrossRef Medline

Macrae M, Kehoe EJ (1999) Savings after extinction in conditioning of the rabbit's nictitating membrane response. Psychobiology 27:85-94.

Maren S (2000) Auditory fear conditioning increases CS-elicited spike firing in lateral amygdala neurons even after extensive overtraining. Eur J Neurosci 12:4047-4054. CrossRef Medline

Maren S (2011) Seeking a spotless mind: extinction, deconsolidation, and erasure of fear memory. Neuron 70:830-845. CrossRef Medline

Maren S, Chang CH (2006) Recent fear is resistant to extinction. Proc Natl Acad Sci U S A 103:18020-18025. CrossRef Medline

Maren S, Quirk GJ (2004) Neuronal signalling of fear memory. Nat Rev Neurosci 5:844-852. CrossRef Medline

McDonald AJ (1982) Neurons of the lateral and basolateral amygdaloid nuclei: a Golgi study in the rat. J Comp Neurol 212:293-312. CrossRef Medline

McGaugh JL (2000) Memory-a century of consolidation. Science 287: 248-251. CrossRef Medline

McKernan MG, Shinnick-Gallagher P (1997) Fear conditioning induces a lasting potentiation of synaptic currents in vitro. Nature 390:607-611. CrossRef Medline

Medina JF, Repa JC, Mauk MD, LeDoux JE (2002) Parallels between cerebellum- and amygdala-dependent conditioning. Nat Rev Neurosci 3:122-131. CrossRef Medline

Milad MR, Quirk GJ (2002) Neurons in medial prefrontal cortex signal memory for fear extinction. Nature 420:70-74. CrossRef Medline

Miserendino MJ, Sananes CB, Melia KR, Davis M (1990) Blocking of acquisition but not expression of conditioned fear-potentiated startle by NMDA antagonists in the amygdala. Nature 345:716-718. CrossRef Medline

Myers KM, Davis M (2007) Mechanisms of fear extinction. Mol Psychiatry 12:120-150. CrossRef Medline

Myers KM, Ressler KJ, Davis M (2006) Different mechanisms of fear extinction dependent on length of time since fear acquisition. Learn Mem 13: 216-223. CrossRef Medline

Napier RM, Macrae M, Kehoe EJ (1992) Rapid reaquisition in conditioning of the rabbit's nictitating membrane response. J Exp Psychol Anim Behav Process 18:182-192. CrossRef Medline

Nicolelis MA, Dimitrov D, Carmena JM, Crist R, Lehew G, Kralik JD, Wise SP (2003) Chronic, multisite, multielectrode recordings in macaque monkeys. Proc Natl Acad Sci U S A 100:11041-11046. CrossRef Medline

Oyama K, Hernádi I, Iijima T, Tsutsui K (2010) Reward prediction error coding in dorsal striatal neurons. J Neurosci 30:11447-11457. CrossRef Medline

Pape HC, Pare D (2010) Plastic synaptic networks of the amygdala for the acquisition, expression, and extinction of conditioned fear. Physiol Rev 90:419-463. CrossRef Medline

Paré D, Collins DR (2000) Neuronal correlates of fear in the lateral amygdala: multiple extracellular recordings in conscious cats. J Neurosci 20: 2701-2710. Medline

Paré D, Gaudreau H (1996) Projection cells and interneurons of the lateral and basolateral amygdala: distinct firing patterns and differential relation to theta and delta rhythms in conscious cats. J Neurosci 16:3334-3350. Medline

Paré D, Quirk GJ, Ledoux JE (2004) New vistas on amygdala networks in conditioned fear. J Neurophysiol 92:1-9. CrossRef Medline

Paton JJ, Belova MA, Morrison SE, Salzman CD (2006) The primate amygdala represents the positive and negative value of visual stimuli during learning. Nature 439:865-870. CrossRef Medline

Pavlov IP (1927) Conditioned reflexes: an investigation of the physiological activity of the cerebral cortex. London: Oxford UP.

Pearce JM, Hall G (1980) A model for Pavlovian learning: variations in the effectiveness of conditioned but not of unconditioned stimuli. Psychol Rev 87:532-552. CrossRef Medline

Quirk GJ, Mueller D (2008) Neural mechanisms of extinction learning and retrieval. Neuropsychopharmacology 33:56-72. CrossRef Medline

Quirk GJ, Repa C, LeDoux JE (1995) Fear conditioning enhances shortlatency auditory responses of lateral amygdala neurons: parallel recordings in the freely behaving rat. Neuron 15:1029-1039. CrossRef Medline

Quirk GJ, Armony JL, LeDoux JE (1997) Fear conditioning enhances different temporal components of tone-evoked spike trains in auditory cortex and lateral amygdala. Neuron 19:613-624. CrossRef Medline

Quirk GJ, Garcia R, González-Lima F (2006) Prefrontal mechanisms in extinction of conditioned fear. Biol Psychiatry 60:337-343. CrossRef Medline

Reijmers LG, Perkins BL, Matsuo N, Mayford M (2007) Localization of a stable neural correlate of associative memory. Science 317:1230-1233. CrossRef Medline

Repa JC, Muller J, Apergis J, Desrochers TM, Zhou Y, LeDoux JE (2001) Two different lateral amygdala cell populations contribute to the initiation and storage of memory. Nat Neurosci 4:724-731. CrossRef Medline

Rescorla RA (2001) Retraining of extinguished Pavlovian stimuli. J Exp Psychol Anim Behav Process 27:115-124. CrossRef Medline

Rescorla RA, Wagner AR (1972) A theory of Pavlovian conditioning: variations in the effectiveness of reinforcement and nonreinforcement. In: Classical conditioning II: current research and theory (Black AH, Prokasy WF, eds), pp 64-99. New York: Appleton-Century-Crofts.

Rogan MT, Stäubli UV, LeDoux JE (1997) Fear conditioning induces associative long-term potentiation in the amygdala. Nature 390:604-607. CrossRef Medline

Rogan MT, Leon KS, Perez DL, Kandel ER (2005) Distinct neural signatures for safety and danger in the amygdala and striatum of the mouse. Neuron 46:309-320. CrossRef Medline

Rosenkranz JA, Moore H, Grace AA (2003) The prefrontal cortex regulates lateral amygdala neuronal plasticity and responses to previously conditioned stimuli. J Neurosci 23:11054-11064. Medline

Sacco T, Sacchetti B (2010) Role of secondary sensory cortices in emotional memory storage and retrieval in rats. Science 329:649-656. CrossRef Medline

Schafe GE, LeDoux JE (2000) Memory consolidation of auditory pavlovian fear conditioning requires protein synthesis and protein kinase $\mathrm{A}$ in the amygdala. J Neurosci 20:RC96. Medline

Schafe GE, Atkins CM, Swank MW, Bauer EP, Sweatt JD, LeDoux JE (2000) Activation of ERK/MAP kinase in the amygdala is required for memory consolidation of pavlovian fear conditioning. J Neurosci 20:8177-8187. Medline

Schoenbaum G, Chiba AA, Gallagher M (1999) Neural encoding in orbitofrontal cortex and basolateral amygdala during olfactory discrimination learning. J Neurosci 19:1876-1884. Medline

Sotres-Bayon F, Quirk GJ (2010) Prefrontal control of fear: more than just extinction. Curr Opin Neurobiol 20:231-235. CrossRef Medline

Sotres-Bayon F, Cain CK, LeDoux JE (2006) Brain mechanisms of fear extinction: historical perspectives on the contribution of prefrontal cortex. Biol Psychiatry 60:329-336. CrossRef Medline

Sotres-Bayon F, Bush DE, LeDoux JE (2007) Acquisition of fear extinction requires activation of NR2B-containing NMDA receptors in the lateral amygdala. Neuropsychopharmacology 32:1929-1940. CrossRef Medline

Tseng WT, Yen CT, Tsai ML (2011) A bundled microwire array for longterm chronic single-unit recording in deep brain regions of behaving rats. J Neurosci Methods 201:368-376. CrossRef Medline

Tsvetkov E, Carlezon WA, Benes FM, Kandel ER, Bolshakov VY (2002) Fear conditioning occludes LTP-induced presynaptic enhancement of synaptic transmission in the cortical pathway to the lateral amygdala. Neuron 34:289-300. CrossRef Medline

Zhou Y, Won J, Karlsson MG, Zhou M, Rogerson T, Balaji J, Neve R, Poirazi P, Silva AJ (2009) CREB regulates excitability and the allocation of memory to subsets of neurons in the amygdala. Nat Neurosci 12:14381443. CrossRef Medline 